\title{
ASCETICISM POETRY BETWEEN IMAM SHAFI'I AND ABU AL-ATAHEYA A COMPARATIVE STUDY
}

\section{شعر الزها بين الإمام الثافعي وأبي العتاهية \\ دراسة مقارنة}

Sekou Kouyate

King Saud University, Riyadh, Saudi Arabia jelifama@gmail.com

\section{ABSTRACT}

The research aims to compare the two poets in terms of social, religious, cultural, economic, and psychological factors and then talk about the similar poetic contents of both poets within the framework of ascetic poetry. The researcher used the French school curriculum, in which the comparison is made between literature that is related to each other based on impact and influence. The most prominent result of the study was that Abu Al-Atheya was influenced by imam shafi'i in some aspects of his poem, but he invented and mastered it perfectly.

Keywords: The Poetry of Asceticism, Imam Shafi'i, Abu al-Ataheya, Comparative Literature.

\section{الملخص}

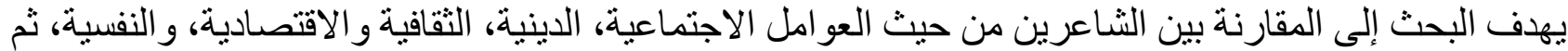

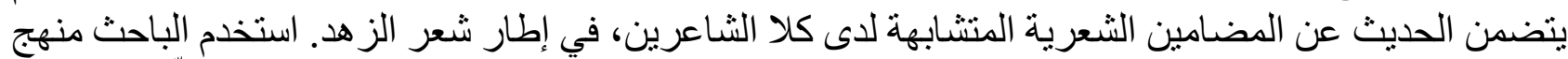

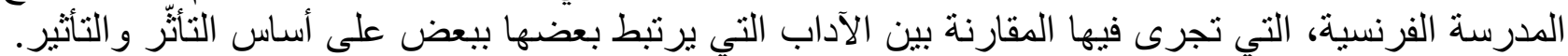

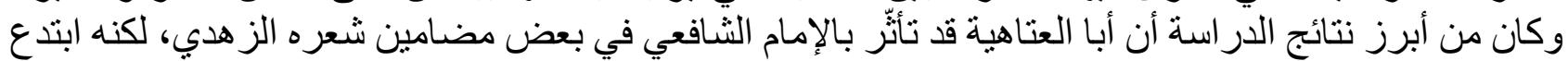

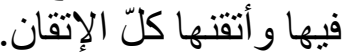

$$
\text { الكلمات المفتاحية: شعر الزهد، الإمام الثافعي، أبو العتاهية، الأدب المقارن. }
$$

\begin{tabular}{|c|c|c|c|}
\hline $\begin{array}{c}\text { FIRST RECEIVED: } \\
\text { 22 May 2020 }\end{array}$ & REVISED: & ACCEPTED: & PUBLISHED: \\
13 June 2021 & 22 June 2021 & 31 October 2021 \\
\hline
\end{tabular}

وتناولت المقدمة موضوع البحث وخطته،

ومنهجه، وتساؤلاته، وتتاول المبحث الأول

المقدمة

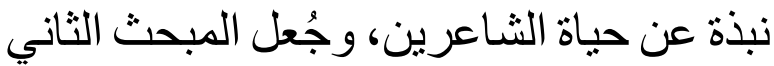

لتحليل المضامين الزهدية من خلال النماذج

يقوم البحث على مقارنة تطبيقية بين

المختارة لكل منهما.

الثـاعر الإمام الثافعي، وأبي العتاهية في

و أما منهج الدراسة، فالدراسة تقوم على ملى

إطار الثعر الزهدي، وقد اقتضت طبيعة

أسـاس المدرسة الفرنسية، التي تجرى فيها

البحث أن يتكون من مقدمة، ومبحثين، 
يعيش عيش المتهنكين ويجري مجرى أهل الخلاعة و المجون، و أنه سمي بأبي العتاهية؛

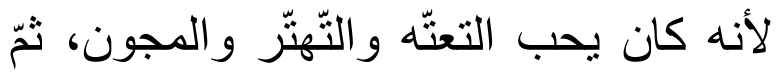

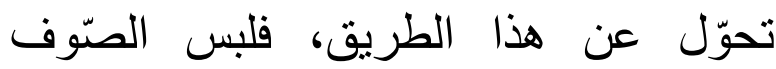
و انصرف إلى الز هد و التقتشف (2)، لكن سلوكه تميّز بتناقض فاضح بين التظاهر بالزه هد والدعوة إلى التجرّد و وعمل البرّ، وبين البخل بلن

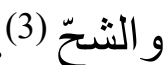

المطلب الثاني: أسباب نزعتهما الزهدية: الفرع الأول: العوامل الاجتماعية، الاينية، الثقافية والاقتصادية:

إن حياة الإمام الثافعي الاجتماعية تشبها

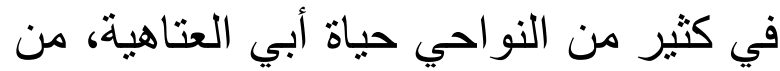
حيث كثرة الفرق و المذاهب الدينية والانحلال

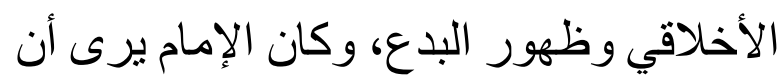
الترابط الاجتماعي بين الناس أصبح ضعيفا، الإناء وإزاء هذا الوضع على الإنسان أن يعايش

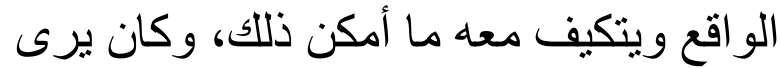

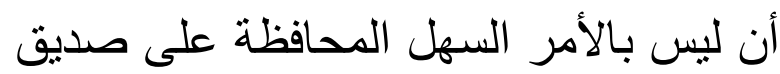
ما لم تخفض جناحك وتغضي عن كثير من بن الأمور، وللثافعي في ذلك درس مطوّل ألقاه

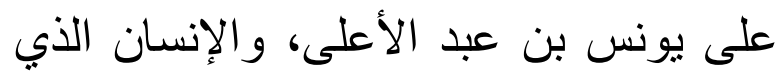
تحتاج إلى مدار اته ليس بأخ للك و إرضاء الإنساء الناس لا سبيل إليه، ولذلك فعليك بما بينفحك فالزمه، وبهذه الوصايا و غير ها برشد الإمام لإئ

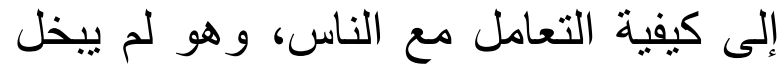

المقارنة بين الآداب التي يرتبط بعضها ببعض ها

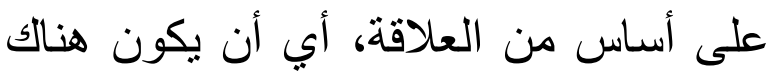

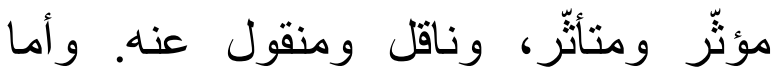

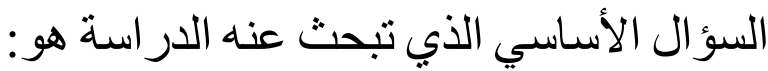
هل نأثر أبو العتاهية في شعره الزي هدي بالإمام

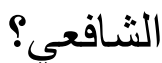
المبحث الأول: نبذة عن حياة الثاعرين: المطلب الأول: تعريف موجز بالشاعرين: الثافعي، هو محمد بن إدريس الإمام: بأفرين: (150هـ - 204ه)، هو إمام لمذهب فقهي، وقد الدئ شغّله الفقه بكامله، ولكنه نظم الشعر وكان له دورا في حياته لأن شعره كان يغطّي مساحة وكنة

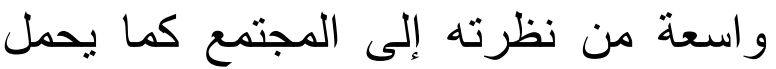

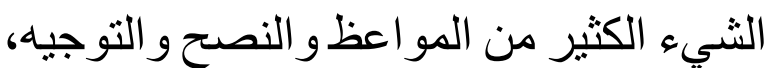
نشأ في حجر أمه في قلّة عيش وضئ اعنيق المال. كان عالما بالقر آن و الحديث و التفسير و واثل والعربية

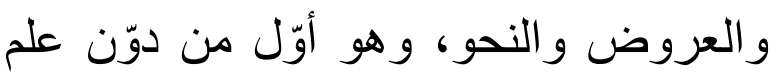

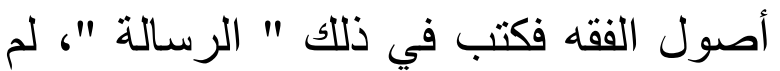

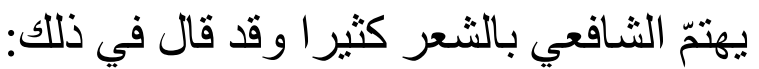

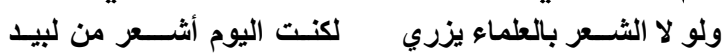
و على نقيض من أبي العتاهية، كان الإمام

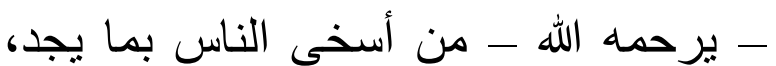

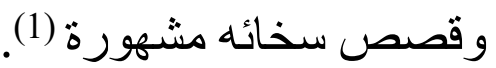

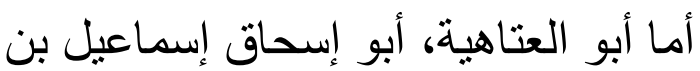
القاسم بن سويد بن كيسان العنزي العيني

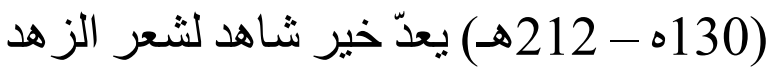

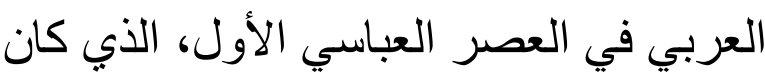

(3) بنظر: عطا الله، سمير: أبو العتاهية بالفرنسية. جريدة

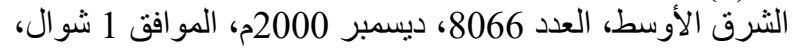
1421هـ تاريخ الاطلاع: 1440/6/29 هـ. الموقع الإلكتروني: http://archive.aawsat.com/leader.asp?section=3 \&article $=19177 \&$ issueno $=8066$ \#.XIAWpurAPIU
(1) ينظر: الثامي: صالح أحمد: مو اعظ الإمام الثافعي. تاريخ الاطلاع: 1440/6/29 هـ. الموقع الإلكتروني: https://www.wattpad.com/3684235 (2) ينظر: ضيف، شوقي: الفن ومذاهبه في الثعر العربي.

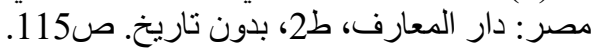


السماوية، فلعل أبا العتاهية قد تأثّرّ بهذه

الديانات و الثقافات في مرحلة من حياته(6).

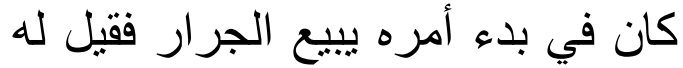
(الجرار) ثم اتصل بالخلفاء وعت فئ مكانته عندهم (7) (لفرد (ر)

الفرع الثاني: العوامل التفسية:

كانت حالات الإمام الثافعي النفسية

و استعداداته الفطرية مختلفة عما سنر اها عند أبي العتاهية، حيث اقتضت تربيته منذ صغره أن يختار هذا المذهب الزها هدي. وإذا إذا ما تتبّعنا ديو ان الثنافعي - رحمه الله - نجد أنه لم بنظم النه إلا في الأغراض التعليمية الدينية الخُلقية

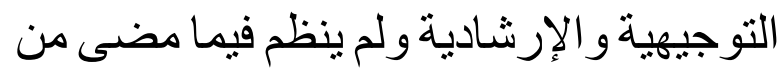
الأغراض التي ذكرناها لأبي العتاهية من فن فن

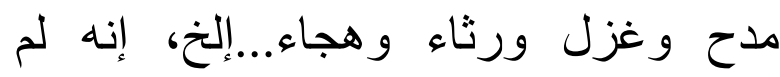
ينصرف للانيا قط؛ لأن طبيعة نشأنه لم تكن

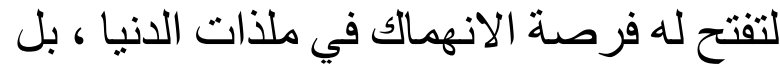
أعدّته ليكون حاملا همّ توجيه الناس وتعليمه

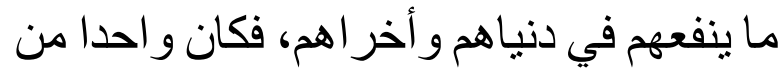

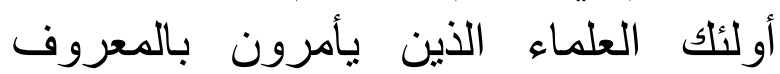
وينهون عن المنكر ويرون في ذللك من بن فيرن واجبات هذا الدين، فقيامه بنظم قصائد تحمل

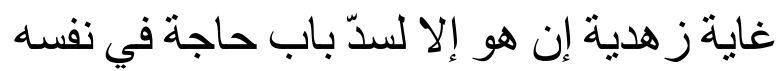
وهي مهمة الوعظو تقديم النصيح للناس. ومن الجوانب النفسية التي كانت تشغل بال الإمام وكان تأكيده عليها متكرّر ا: العقيدة و العلم وذكر الآخرة، هذا بالإضافة إلى تقديم ما ينفع الناس من النصح في دنياهم و أخر اهم

(6) ينظر: ضيف، شوقي: تاريخ الأدب العربي. مصر: دار

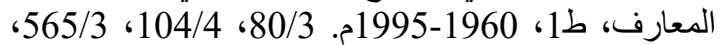

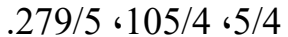
(7) ينظر: الزركلي، خير الدين: الأعلام. دار الملايين، ط15/4، .321/1.2002
بنصائحه في سبيل تبصير المسلم بكيفية أداء دوره في الحياة الاجتماعية بشكل فاعل(4) بكائل فالثافعي كإمام وفقيه لفت انتباهاه هذه

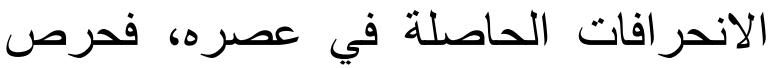
على توجيه الناس بشتى الأساليب شعرًا ونثرًا. مات أبو الإمام - رحمهما الله - وهو صغير فحملته أمه إلى مكة وهو الإمان سندان سنتين لئلا يضيع نسبه، فنشأ بها وقر أ القرآن وهو آنه ابن سبع سنين (5)، فهذا يعني أن أمّه قد

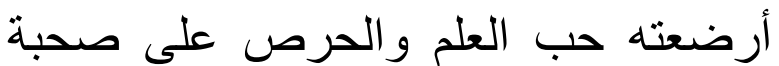
العلماء، ولم تصرفه عن ذلك لدنيا يصيبها أو الو حرفة يكتسب منها رغم يتمه وفقره. أما أبو العتاهية، فقد نشأ في بيئة كانت هنالك طبقة تغرق في الترف و النعيم، و وكان جمهور الشعب يعيش في الضّنك والبؤس، وظلت الحياة العقلية مزدهرة بما نقل وما كان ينقل من الثقافات الأجنبية، مما هيّأ لظهور فلاسفة عظام و علماء بار عين في جميع العلوم اللغوية والبلاغية والنقدية والتاريخية والإسلامية والكلامية، وكثر حينئذ النساك و الز هاد في متاع الحياة الدنيا، و عاثشو ا معيشة كلها شظف وتقشف وتنتل و عبادة، ومن آثنار الحركة العلمية في هذا العصر ظهور المذاهب الأربعة، المالكية و الحنفية و الثنافعية و الحنبلية، كما اتسم العصر الذي عاش فيه أبو العتاهية بالحرية الدينية، بحيث نرى فيها لاعيه المذاهب المتعدّدة والفرق المتجدّدة و الديانات

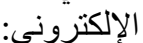

https://www.wattpad.com/3684235 http://ar.wikipedia.org (5) محمد بن إدريس الثنافعي. 


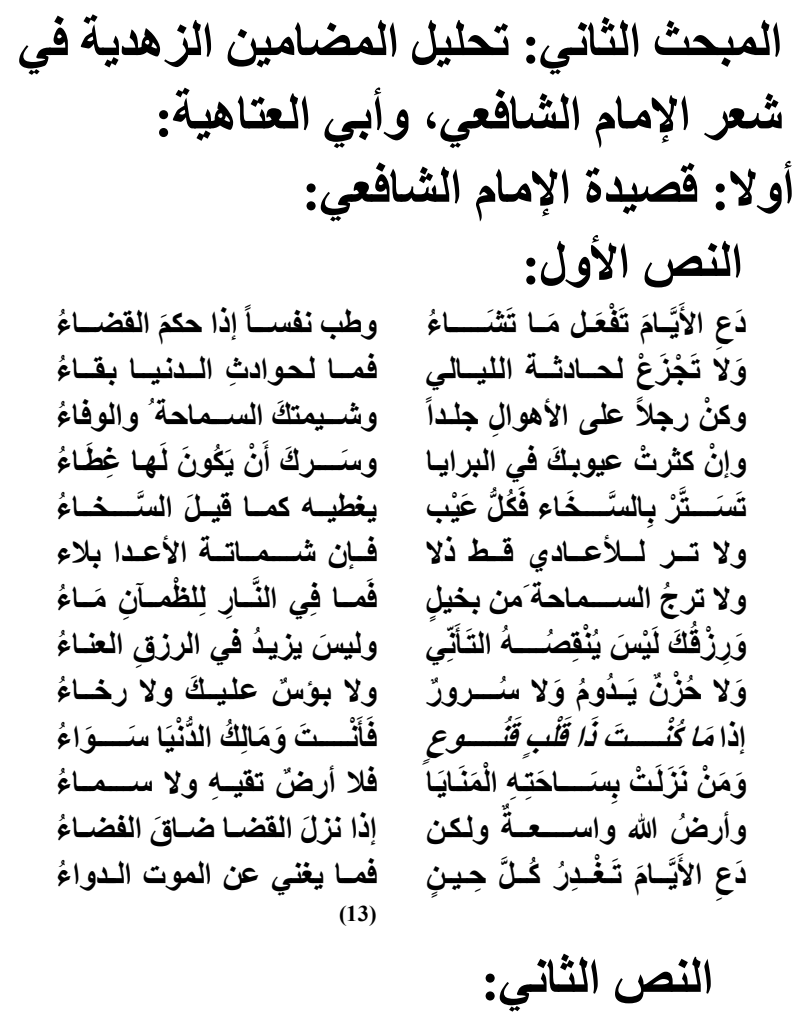

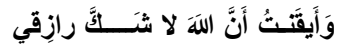

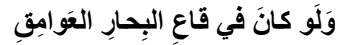

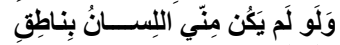

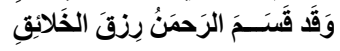

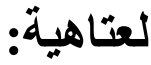

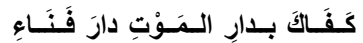

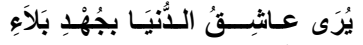

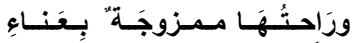

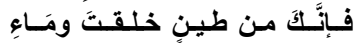

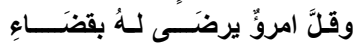

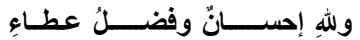

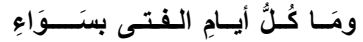

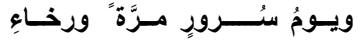

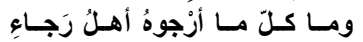

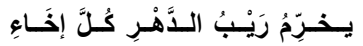

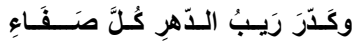

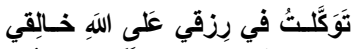

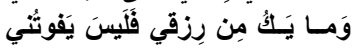

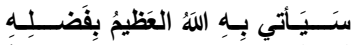

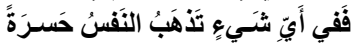

من النصح والإرشاد، كمدح القناعة وذّم الطمع... إلخ (8). وتظهر لنا حياة أبي العتاهية في مظهرين متباينين: حياة الغزل ومعاقرة

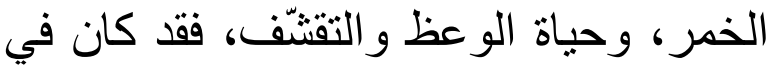

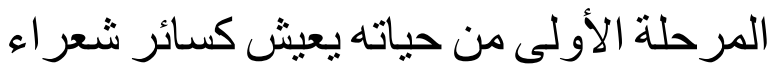
عصره، يمدح ويرثي ويتغزّل، أشعاره في

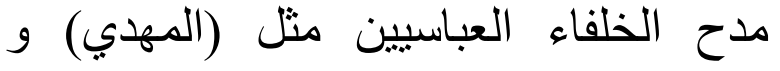
(الهادي) و (الرشيد) و (المأمون)، أما الغزل العنيل فتدلّ على انصر افه في أول عهده إلى ولى حياة) اللهو والتهنك، واشتنهر بها حتى زعموا أنها كني بأبي العتاهية لأنه كان يحب التهن التهن

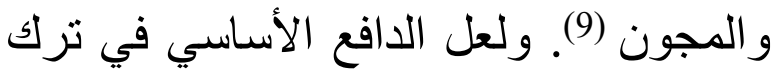
سيرته الأولى هو فثنله في حبّه لـ الـ (عُنبة) جارية المهدي (10)، فيقول المعرّي في هذئ فئه الثنأن: - (الن
و هذا أبو العتاهية يشير إلى ما تحمّل من الألم و الهجر في حبّ عتبة:

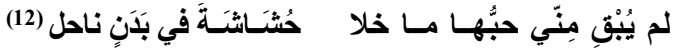
إضـافة إلى ذللك، ربما إر ادته التميزّ عن التهن معاصريه الذين انغمسو ا في اللهو و اللعب، من التئ

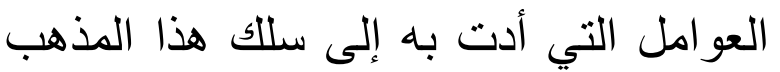

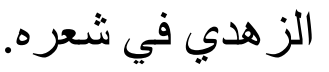

(11) المعري، أبو العلاء: شرح اللزوميات. تحقيق: سيدة حامد، الاعن،

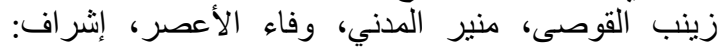

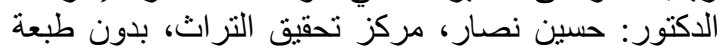

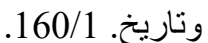

(12) أبو العتاهية: ديوان أبي العتاهية. بيروت: دار بيروت للطباعة

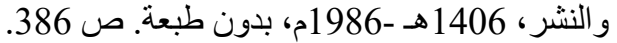

(13) الثنافعي، محد بن إدريس: ديوان الإمام الثافعي. ص 39 39-
(8) ينظر : الثافعي، محمد بن إدريس: ديو ان الإمام الثشافعي. جمعه لديه

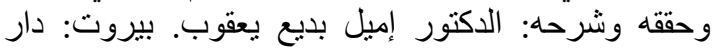

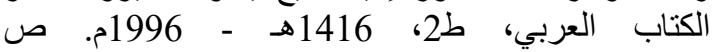
.88،89،115،95،112

$$
\text { (9) ينظر : ضيف، شوقي: تاريخ الأدب العربي. 240/3، } 249 .
$$
(10) ينظر : المرجع السابق. 239/3.

$$
\text { (14) المصدر السابق. ص } 109 .
$$


البداية والنهاية: "ثم عاد الثافعي إلى العراق

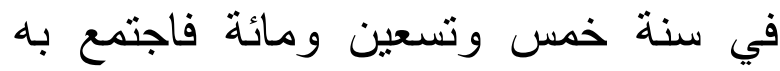
جماعة من العلماء هذه المرة منهم أحمد بن بن فئ فئ

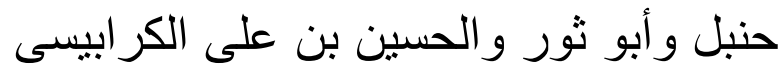
و الحارث بن شريح البقال وابو عبد وليد الرحمن

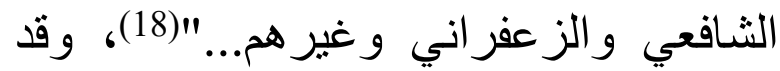
تأثر به علماء كثيرون منهم أبو ثور إبر الهير اهيم

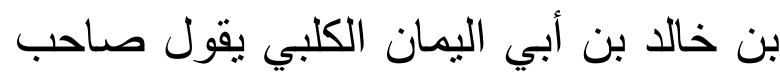
كتاب (تاريخ ابن الوردي): "... فيها نوفي أبو البون ثور إبراهيم بن خالا بن أبي اليمان الكلبي الئي الفقيه البغدادي صاحب الإمام الثنافعي وناقل أقو اله القديمة عنه وكان على مذهب أهل

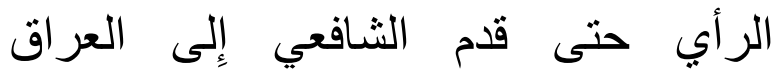
فاتبعا..."(19). كل هذا يؤيّد قولنا بتأثّرّ أبي

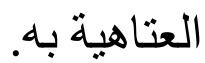

تللك المضامين الزهدية التي أنثدها أبو

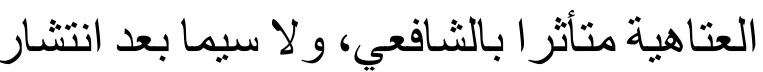

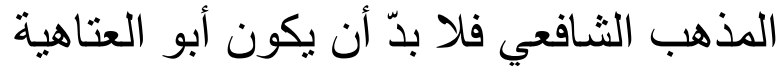
بثقافته العربية الواسعة قد طالعه مرارًا وتكرارًا، ومن أبرز تللك المضامين:

\section{1-الرضا بالقضاء والقدر:} يقول الشافعي:

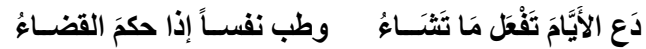

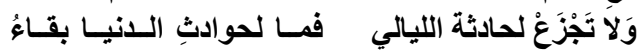

يشير الإمام في هذين البيتين إلى أنه لا

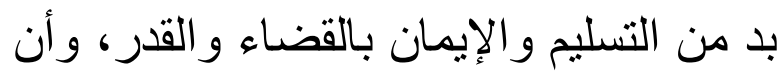
مصائب الليالي ونو ائبها الليالي، سوف تزاء ولفئل

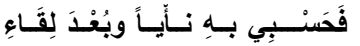

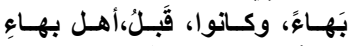

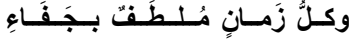

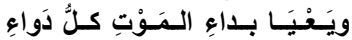

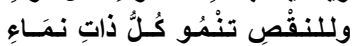

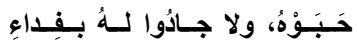

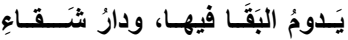

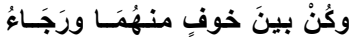

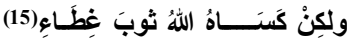

ثانيا: ملامح تأثرّ أبي العتاهية بالإمام

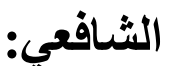

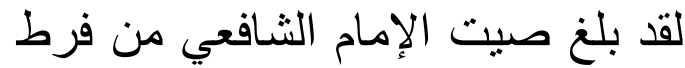
الذيوع ما بلغ، قال أيوب أبو يعقوب البوبطي:

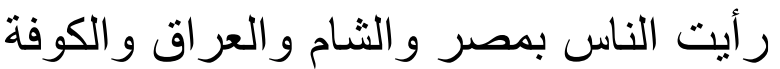

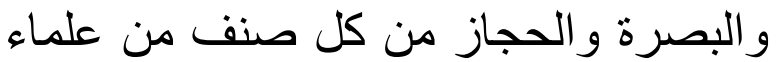
القرآن والققه ولسان العرب و السير و الكلام

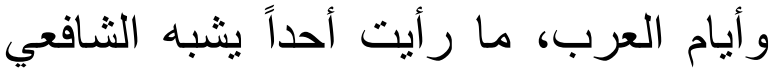
(16)، هذا بعني أن الإمام كان معروفا في كل العام المان هذه الأقطار المذكورة وإذا كان أبو العتاهية

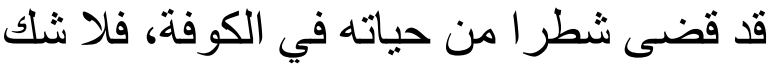

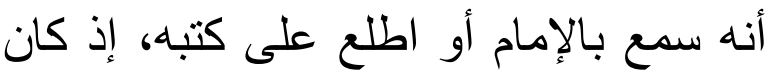

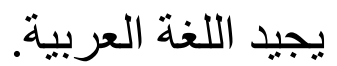

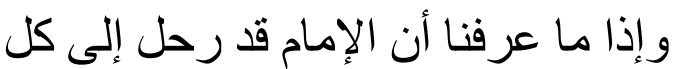
من مصر ومكة، والمملكة العربية السعودية تحدّها العراق من الثمال (17)، وقد انتقل أبو الثما

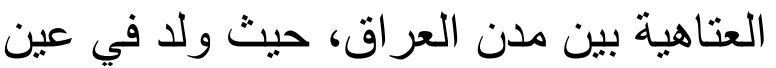

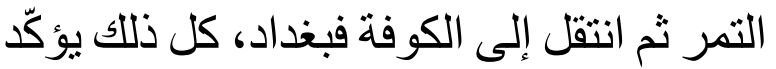

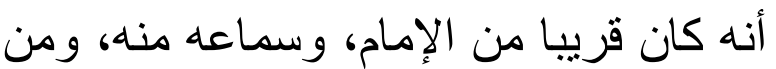

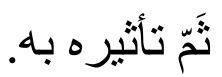
ولنذهب إلى أبعد من ذلك، فقد رحل الإمام إلى العر اق أكثر من مرة يقول صناحب دلف فل رحل
(18) أبو الفداء: إسماء بن عمر: البداية والنهاية. بيروت: مكتبة المعارف، بدون طبعة وتاريخ. 252/10.

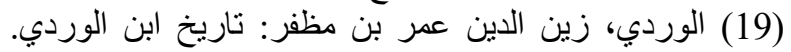

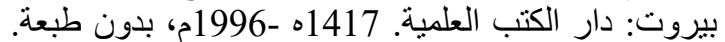
.217/1

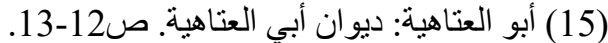

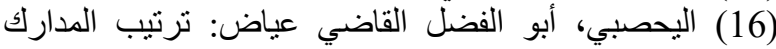

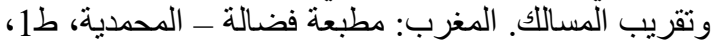
185/3.1970-1966 http://ar.wikipedia.org (17) 


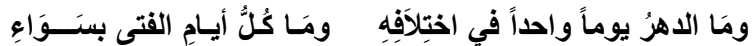

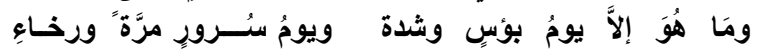

والاقتباس في هذين البيتين و اضح، فقد اقتبس الثَاعر قوله تُعالى: ( فَإنَّ مَعَ الْعُشْرِ

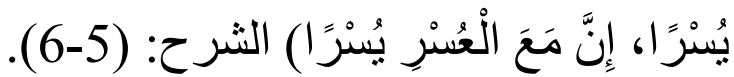

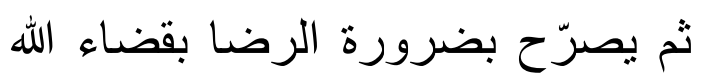

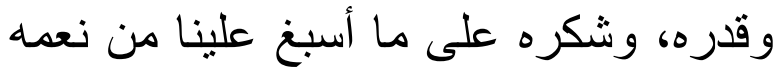
و عدم الكفر ان بها، فيقول:

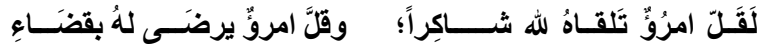

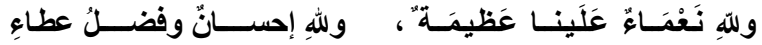

\section{2- ل - لزوم الصبر على الأهوال:

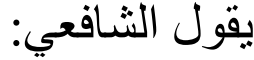

وكنْ رجلاً على الأهوالِ جلداً وشيمتلكَ السماحةُ و الوفاوُ

بطالب الثناعر المرء في صدر البيت أن

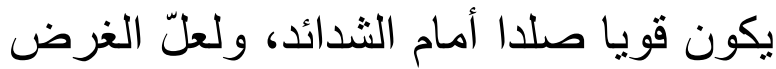
من تخصيص الثاعر الرجل بالخطاب دون المرأة، كون صفة القوة والتصلّد تكمن في التحل

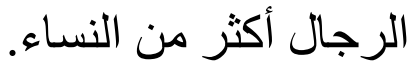

ويشير أبو العتاهية إلى المضمون نفسه،

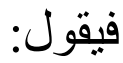

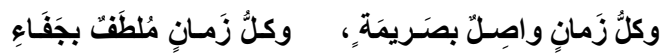

فالزمان محفوف بالجدّ والصعاب، وما

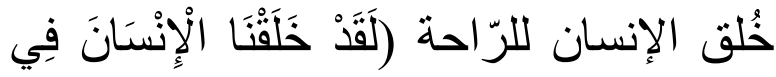

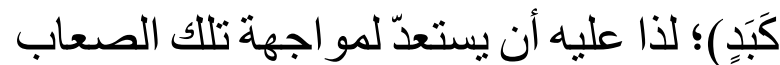
بالصبر و السماحة. 3-الرزق بيد الله: يقول الثافعي:
فلا بقاء لها، وهي سنة الله في أرضه. وقد وظّّف أبو العتاهية معنى القضاء بشكل فئل مشابه

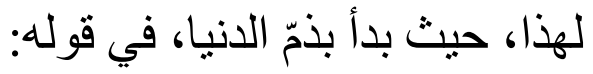

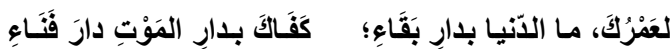

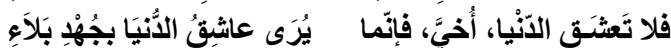

فعاثق الدنيا لا يخلو عن مصائب، فكأنّما استخدم صيغة التصغير في لفظة (أخي) للتقليل من شأن عاثنق الدنيا. ولعلّ غرض الثاعر من هذه المقدمة، التي صاغها لاغها لذم الدنيا، هو تهيئة ذهن المخاطب هلاعن لاستيعاب معنى القضاء والقدر، فالمرء عندما يكره لئه

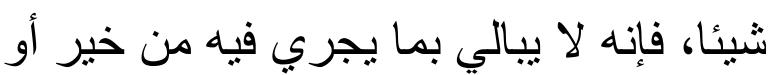
شرّ، و ولا يبدي له اهتمامًا. وبعد هذه المقدّمة، شرع الثناعر شيئا فتشيئا إلى توظيف دلالة الإيمان بالقدر في

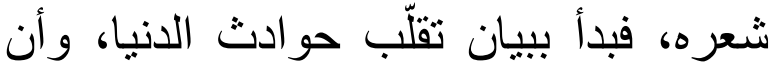
الأيام ليست كلها سواء يوم للك ويوم عليك

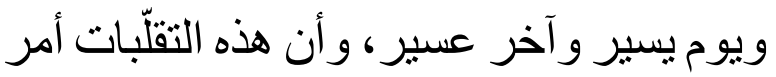
إلهي، لا نستطيع تغيير ها، بل علينا الإيمان بقضاء الله وقدره، يقول:

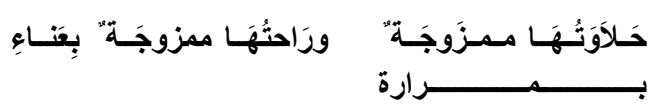

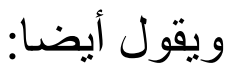

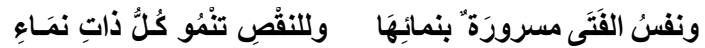

فالعمر كلما ازداد نقص، وما خُلقنا

للبقاء، بل ثمة يوم آخر غير اليوم: (فما

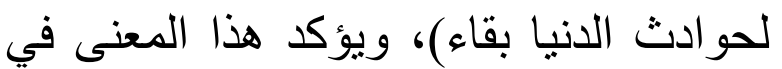
أبيات أخرى، حيث يقول: 
لن يزيد في الرزق شيئا، كما أن السخاء لن ينقصه كذلك.

و لأبي العتاهية بيت يُجمل المعنى نفسه،

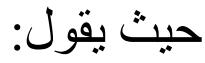

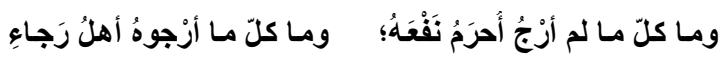

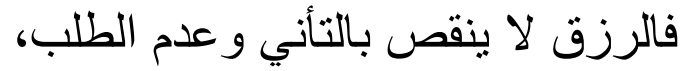

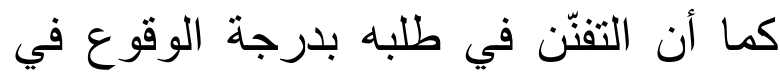

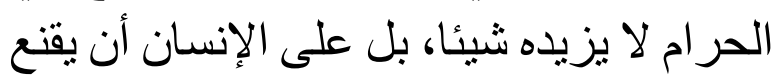

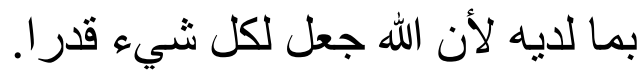

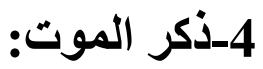

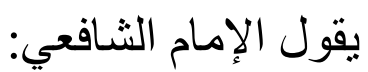

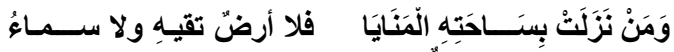

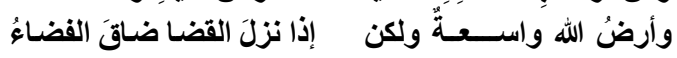

فالأرض الفسيحة تضيق إذا نزل القضاء، وما حكم الله للإنسان. ثم ذكر خيانة

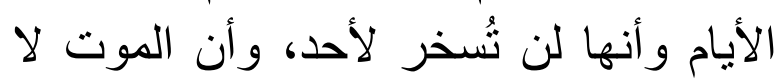
يغني عنه دواء طبيب، فقال:

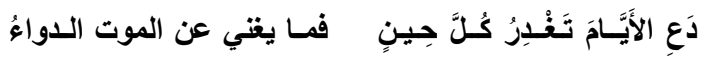

ونجد أبا العتاهية، يصوغ المعنى نفسه،

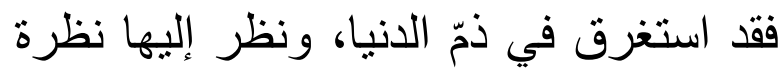

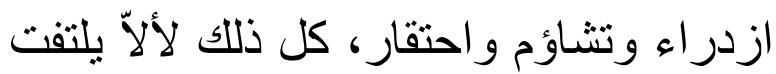

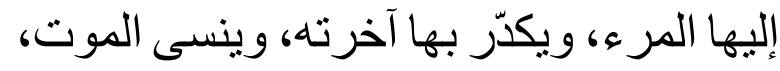

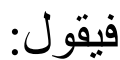

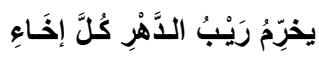

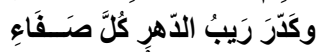

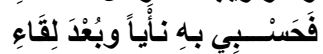

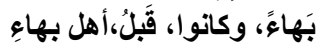

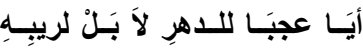

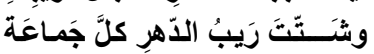

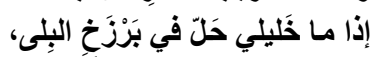

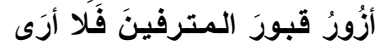

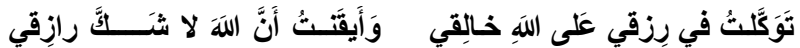

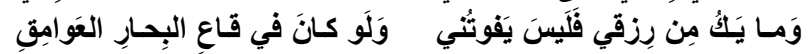

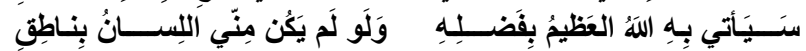

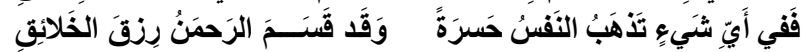

فالرزق بيد الله، ولا يفوت المرء ما قد

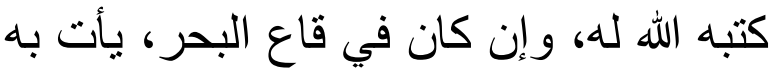
الله. ويقول الثنافعي أيضا:

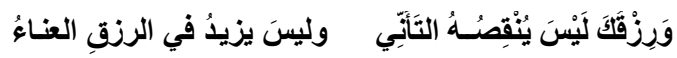

فالتمهل في طلب الرزق لا ينقصه،

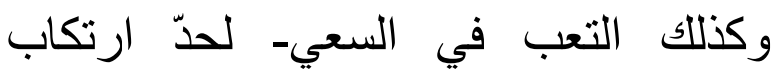

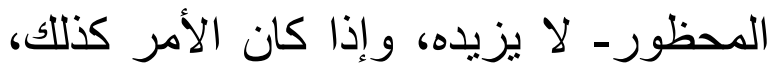

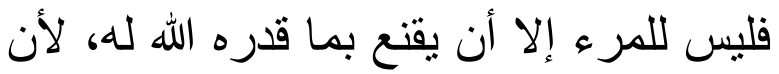
القناعة من أجلّ ما يملك الإنسان في الحياة، لمَّه يقول الثافعي:

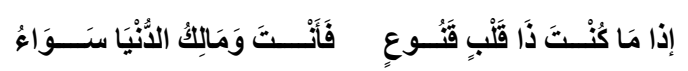

ثم يشرع الثاعر في ذكر فضائل السخاء،

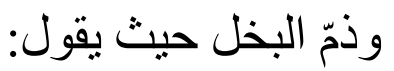

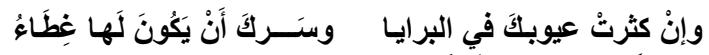

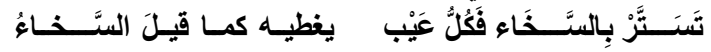

فبالجود و الكرم يستطيع المرء إخفاء عيوبه على أعدائه، و الناس كافة.

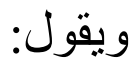

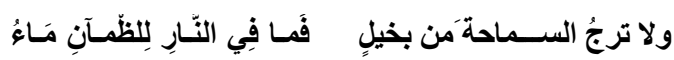

يحاول الشاعر ـ عن طريق المقارنة بين

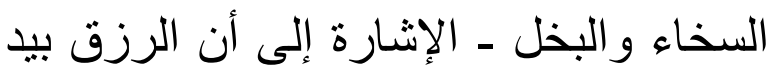

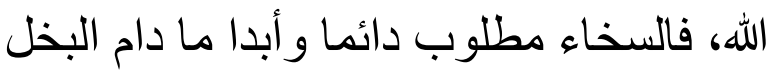


2- أما من حيث النظر إلى الدنبا، فقد كان النافعي ينظر إليها نظرة إيجابية، بينما كان ينظر إليها أبو العتاهية نظرة اليجابة بينة تشاؤمية.

3- إن شعر كلا الثّاعرين يمتاز بالسلاسة و العذوبة والانسجام، بعيدا عن الجمود

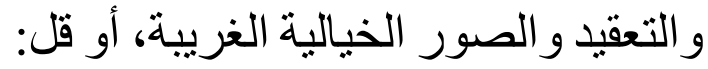
هي أقرب إلى النثر والخطب المنبرية البليغة و الفصيحة منه إلى الثى الخيال الثعري.

المصادر والمراجع أبو العتاهية. (1406هـ -1986م). ديوان أبي العتاهية. بيروت: دار بيروت للطباعة

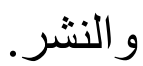

أبو الفداء، إسماء بن عمر. (2002): البداية و النهاية. بيروت. مكتبة المعارف.

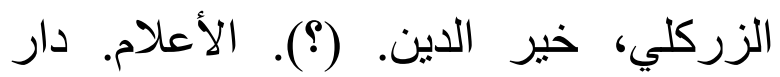

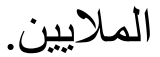

الثنافعي، محمد بن إدريس. (1416هـ - دين

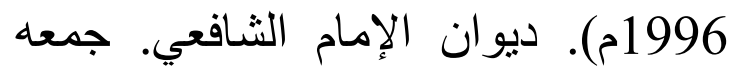
وحققه وشرحه: الدكتور إميل بديع يعقوب. بيروت: دار الكتاب العربي.

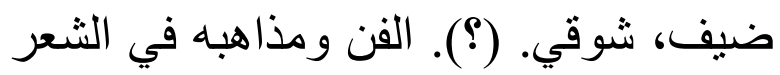

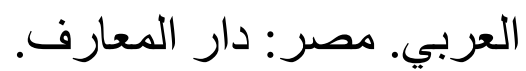

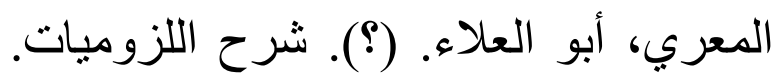

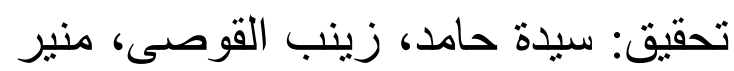
المدني، وفاء الأعصر ، إثراف: الفئ الدكتور: حسين نصار، مركز تحقيق التراث.

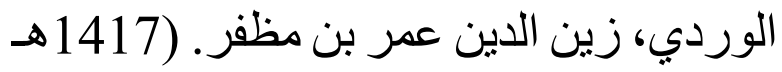

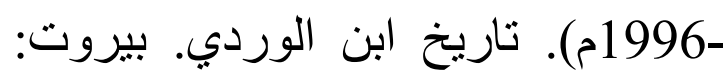
دار الكتب العلمية. - ماريخ

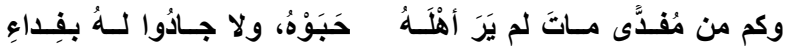

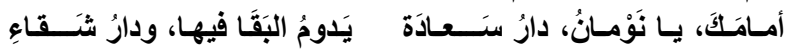

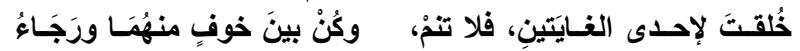

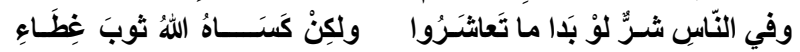

ولعلّ المقصود بكلمة (الثرّ) في البيت البرّ

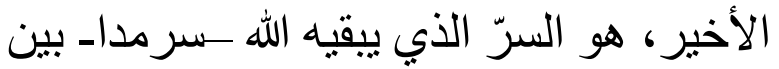
الميت وأهله، فالميت لا لا يدري ماذيه الاذا يجري

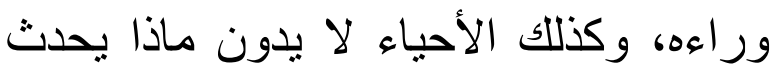
لميتهم. تلك هي المضامين المشتركة في هاتين القصيدتين وقد رأينا كيف تأثر أبو العتاهية ببعض مضامين الثافعي الز هدية، لكنه ألبسها

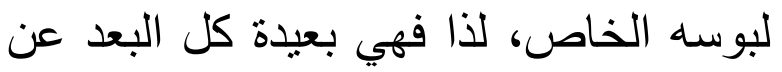

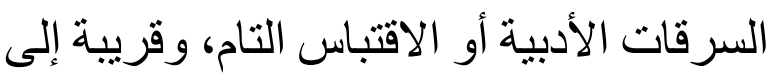
التو ارد الذهني و التأثّرّ.

ثالثا: الأساليب الشعرية لهذين الثاعرين:

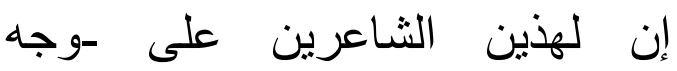
الإجمال- خصائص مشتركة في أسلوب ألوبن

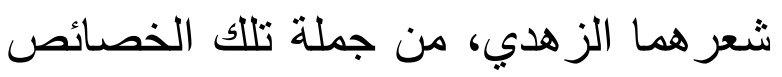

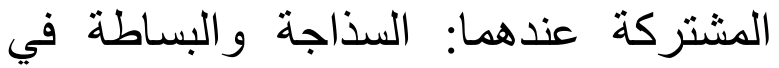

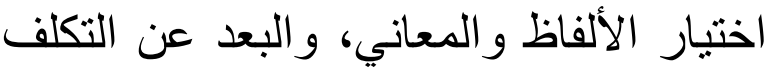
و التعقد و الاقتباس من القرآن، ثمّ عدم التفنّن في استخدام الصور البلاغية.

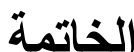

لقد أسفر بحثنا حول المقارنة بين أساليب الثـاعرين الزهدية عن النتائج التالية:

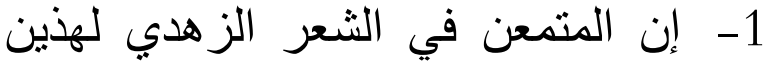

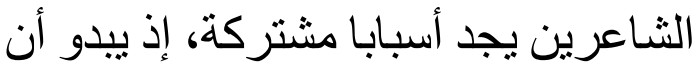

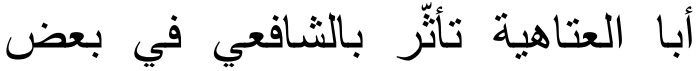

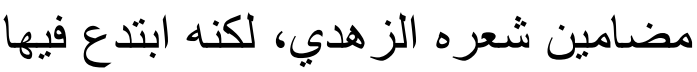
و أتقنها كلّ الإتقان. 


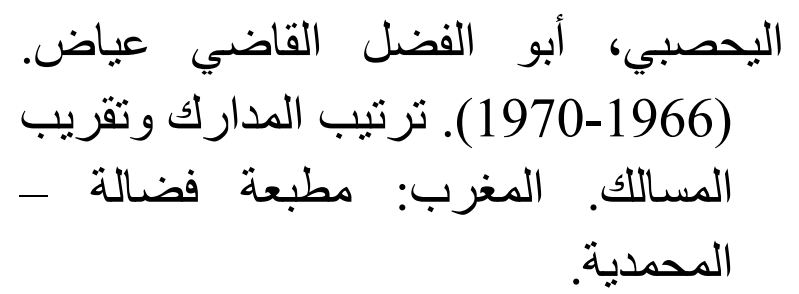

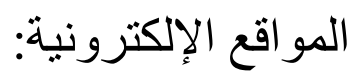

عطا الله، سمير. (2000م). أبو العتاهية بالفرنسية. جريدة الثرق الأوسط، العدد العيو

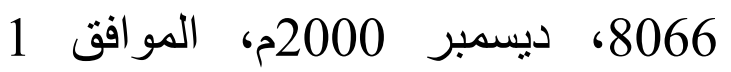

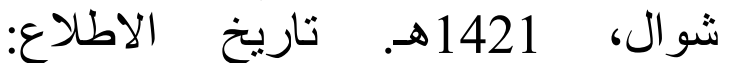
1440/6/29. الموقع الإلكتروني: http://archive.aawsat.com/leader.asp?section= $3 \&$ article $=19177 \&$ issueno $=8066 \#$.XIAWpur

APIU 